\title{
OLIMPÍADAS DE MATEMÁTICA: INCENTIVANDO A PARTICIPAÇÃO DE MAIS MENINAS
}

DOI: 10.37702/2175-957X.COBENGE.2021.3752

Laurete Zanol Sauer - Izsauer@ucs.br

UNIVERSIDADE DE CAXIAS DO SUL

Rua Tarquinio Zambelli 164

95054-410 - Caxias do Sul - RS

Valquíria Villas-Boas - vvillasboas@gmail.com

Universidade de Caxias do Sul

Rua Francisco Getúlio Vargas 1130

95070-560 - CAXIAS DO SUL - RS

Isolda Gianni de Lima - iglima1@gmail.com

Universidade de Caxias do Sul

Rua Guia Lopes, 670, apto 51670

95020-390 - Caxias do Sul - RS

Odilon Giovannini - ogiovannini@gmail.com

Universidade de Caxias do Sul

R. Aguinaldo da Silva Leal 45

95700-358 - Bento Gonçalves - RS

Júlia Giacomet Thomazoni - jugiacomet98@gmail.com

Universidade de Caxias do Sul

Rua Fernão Dias 254

95052-270 - Caxias do Sul - RS

Júlia Bristot Matos - jbmatos1@ucs.br

Universidade de Caxias do Sul

Avenida Alcides Webber 560

95057-550 - Caxias do Sul - RS

Caroline Cichin Spigolon - ccspigolon@ucs.br

Universidade de Caxias do Sul

Rua Alfredo Bedin 38

95030-313 - Caxias do Sul - RS 
Luana Fabian Menegon - Iuanamenegon@hotmail.com

Universidade de Caxias do Sul

Borges de Medeiros 2555

95270-000 - Flores da Cunha - RS

Giovana Rama de Araujo - giovanara03@gmail.com

Universidade de Caxias do Sul

av italia 500

95010-040 - Caxias do Sul - RS

Simone Araldi - simonearaldi@hotmail.com

Universidade de Caxias do Sul

Linha Fagundes Varella 630

95260-000 - Nova Roma do Sul - RS

Júlia Mariá Figueredo Leal - juuuliamfleal@outlook.com

Universidade de Caxias do Sul

Angelo Zulian Sobrinho 335

95095-020 - Caxias do Sul - RS

Resumo: Neste artigo, apresentamos o subprojeto Olimpíada de Matemática que integrou o projeto Encorajando Meninas em Ciências Exatas, Engenharias e Computação, da Universidade de Caxias do Sul. O referido subprojeto contemplou o planejamento e a execução de oficinas de preparação de estudantes para a Olimpíada de Matemática e foi desenvolvido por uma equipe feminina de estudantes de graduação, orientada por professores universitários e auxiliada, na etapa inicial, por um intercambista da Universidade de Verona, Itália. Para o planejamento das oficinas, foram levantados temas recorrentes nas Olimpíadas Brasileiras de Matemática das Escolas Públicas e realizaram avaliações diagnósticas para identificar dificuldades de estudantes das escolas coexecutoras. As oficinas foram desenvolvidas a partir da estratégia de aprendizagem ativa "Desafio em Grupos" para a resolução de dúvidas e problemas já aplicados nas Olimpíadas Brasileiras de Matemática das Escolas Públicas. A cada encontro, o número de membros do grupo era reduzido, para que aos poucos os estudantes pudessem trabalhar individualmente. Após essa etapa de preparação, a equipe feminina de estudantes de graduação selecionou novas questões e auxiliou na organização e condução da mini-olimpíada (Fase 1) de caráter classificatório. Participaram cinco escolas públicas da região de abrangência da UCS, com todos os estudantes interessados e divididos por níveis: Nível 1 para 60 e 70 anos e Nível 
2 para 80 e 90 anos do Ensino Fundamental e Nível 3 para o Ensino Médio. Os três meninos e as três meninas com melhor desempenho em cada nível passaram para a Fase 2, representando suas escolas na Olimpíada de Matemática 2019 da Universidade de Caxias do Sul. Na Fase 2, as estudantes de graduação buscaram questões de Olimpíadas anteriores de maior complexidade para desafiar e destacar os melhores estudantes com medalhas de ouro, prata e bronze, e suas escolas com troféus de primeiro, segundo e terceiro lugar. No desenvolvimento deste importante projeto de estudo e engajamento para os estudantes de cinco escolas coexecutoras, as estudantes de graduação também colaboraram para desenvolver autonomia e autoconfiança nos estudantes das escolas coexecutoras, incentivando-os a participarem da OBMEP.

Palavras-chave: Olimpíadas de Matemática, Aprendizagem Ativa, Oficinas de Matemática. 


\section{OLIMPÍADAS DE MATEMÁTICA: INCENTIVANDO A PARTICIPAÇÃO DE MAIS MENINAS}

\section{INTRODUÇÃO}

Tendo em vista colaborar para melhorar os índices de participação e premiação feminina na Olimpíada Brasileira de Matemática das Escolas Públicas (OBMEP), foram planejadas oficinas de preparação para a Olimpíada de Matemática (OlimMat) na Universidade de Caxias do Sul (UCS), que ocorreram em escolas. A implementação das oficinas ficou a cargo de bolsistas estudantes de graduação, com a supervisão de um mestrando intercambista e de professoras orientadoras. O planejamento e a execução das oficinas, ocorreram em cinco etapas, contemplando momentos de estudos e preparação, na UCS, sede do projeto, com a aplicação das oficinas nas escolas coexecutoras utilizando estratégias de aprendizagem ativa, como desafios em grupos, execução de etapas preliminares da OlimMat nas escolas e, finalmente, a sua realização na universidade, culminando com cerimônia de premiação.

A OBMEP é um projeto de âmbito nacional dirigido a escolas brasileiras, públicas e privadas, promovida pelo Instituto de Matemática Pura e Aplicada (IMPA) e com apoio da Sociedade Brasileira de Matemática (SBM). A OBMEP tem como alguns de seus objetivos principais estimular e promover o estudo da Matemática, contribuir para a melhora da qualidade da educação básica, identificar jovens talentos e incentivar o aperfeiçoamento dos professores das escolas públicas (OBMEP, 2021).

Os participantes a quem se destina a OBMEP são estudantes do 6ํano do Ensino Fundamental até o último ano do Ensino Médio, divididos em níveis, quais sejam: Nível 1 para $6^{\circ}$ e $7^{\circ}$ anos do Ensino Fundamental, Nível 2 para $8^{\circ}$ e $9^{\circ}$ anos do Ensino Fundamental e Nível 3 para alunos do Ensino Médio (OBMEP, 2021). Na primeira fase, que ocorre nas escolas, as provas são compostas por questões objetivas e todos os estudantes das escolas públicas e privadas são convidados a participar. Da segunda fase, participam 5\% dos estudantes com o melhor desempenho na primeira, sendo a prova discursiva e aplicada em locais especificados, fora da escola, designados pela organização nacional.

Uma análise de dados oficiais da OBMEP revela que, desde 2005 (primeiro ano de sua realização), até 2019, a participação das meninas foi sempre inferior à dos meninos.

Quanto às medalhas, a maior porcentagem de meninas medalhistas de ouro foi 23,15\%, em 2016, conforme a Tabela 1.

Tabela 1. OBMEP 2016 - premiações por gênero.

\begin{tabular}{|c|c|c|c|c|c|c|}
\hline \multirow{2}{*}{ Prêmio } & \multicolumn{2}{|c|}{ Gênero Feminino } & \multicolumn{2}{|c|}{ Gênero Masculino } & \multirow{2}{*}{$\begin{array}{c}\text { Não } \\
\text { Informado }\end{array}$} & \multirow{2}{*}{ Total } \\
\hline & Total & $\%$ & Total & $\%$ & & \\
\hline OURO & 116 & 23,15 & 384 & 76,65 & 1 & 501 \\
\hline PRATA & 430 & 28,67 & 1.068 & 71,20 & 2 & 1.500 \\
\hline BRONZE & 1.597 & 35,49 & 2.893 & 64,29 & 10 & 4.500 \\
\hline $\mathrm{MH}$ & 17.130 & 40,32 & 25.281 & 59,51 & 71 & 42.482 \\
\hline
\end{tabular}

Fonte: Autores, com base em dados oficiais da OBMEP (2021).

Ainda assim, um percentual bem abaixo do que foi alcançado pelos meninos, nesse mesmo ano, o que aconteceu também no caso das medalhas prata e bronze. 
Já, a menor porcentagem de medalhas de ouro conquistadas por meninas aconteceu no ano de 2007 , em que o público feminino representava apenas $14,95 \%$, muito abaixo do percentual de meninos, conforme a Tabela 2.

Tabela 2. OBMEP 2007 - premiações por gênero.

\begin{tabular}{|c|c|c|c|c|c|c|}
\hline \multirow{2}{*}{ Prêmio } & \multicolumn{2}{|c|}{ Gênero Feminino } & \multicolumn{2}{|c|}{ Gênero Masculino } & \multirow{2}{*}{$\begin{array}{c}\text { Não } \\
\text { Informado }\end{array}$} & \multirow{2}{*}{ Total } \\
\hline & Total & $\%$ & Total & $\%$ & & \\
\hline OURO & 45 & 14,95 & 256 & 85,05 & 0 & 301 \\
\hline PRATA & 105 & 17,50 & 495 & 82,50 & 0 & 600 \\
\hline BRONZE & 526 & 25,04 & 1.575 & 74,96 & 0 & 2.101 \\
\hline $\mathrm{MH}$ & 10.776 & 35,92 & 19.225 & 64,08 & 0 & 30.001 \\
\hline
\end{tabular}

Fonte: Autores, com base em dados oficiais da OBMEP (2021).

Mesmo quando são analisadas as categorias prata e bronze de premiação, a disparidade continua. No entanto, os dados sobre a classificação para a segunda fase da OBMEP revelam que, desde 2006, nos três níveis, aproximadamente metade dos alunos classificados para a segunda fase são meninas. Portanto, em todas as faixas etárias, aproximadamente metade dos $5 \%$ melhores alunos em matemática são meninas (IMPA, 2019). Considerando que a aplicação da prova, na segunda fase, acontece de maneira igualitária e imparcial, o número de meninos premiados é expressivamente maior.

\section{MÉTODO}

As oficinas de preparação para as Olimpíadas de Matemática, como parte das atividades do programa Encorajando Meninas nas Ciências Exatas, Engenharias e Computação (EMC\&T), tiveram como objetivos o incentivo ao estudo e desenvolvimento de habilidades matemáticas, mas tiveram também um sentindo social para a inserção, incentivo e encorajamento de estudantes meninas a participarem preparando-se para enfrentar o desafio da OBMEP com as mesmas condições e capacidades que os meninos. A aplicação das oficinas por estudantes de graduação, mulheres, que escolheram dedicar suas carreiras às ciências exatas, encoraja as jovens meninas a pensar em Ciência e Matemática como caminhos possíveis, ampliando a representatividade feminina e a consolidação do conceito de igualdade de gênero. Às vezes, mal se imagina o que pode passar a representar na vida de um aluno um simples gesto do professor. O que pode ser um gesto aparentemente insignificante vale como força formadora ou como contribuição à assunção do educando por si mesmo (FREIRE, 1996).

O planejamento das oficinas, na UCS, baseou-se na estratégia de aprendizagem ativa Desafio em Grupos e estruturou-se com base em objetivos de aprendizagem organizados de acordo com a Taxonomia de Bloom, buscando atingir maiores níveis de complexidade. Em sala de aula, nos momentos de aplicação da metodologia, pretendeuse criar um ambiente descontraído, seguro e levemente competitivo a fim de engajar as participantes nas atividades, promover o exercício da cooperação, pois o desempenho dependia de todas na equipe, e contribuir para o desenvolvimento pessoal de cada estudante. Ao final de cada encontro, as integrantes da equipe vencedora eram agraciadas com prêmios simbólicos.

Ainda como parte do planejamento, a opção pela Taxionomia de Bloom, para nortear a prática, teve como objetivo avaliar e estimular o desempenho das estudantes 
em diferentes níveis de construção de conhecimento, explorando o lembrar e o entender na revisão e aprofundamento dos conteúdos teóricos; o aplicar e o analisar na resolução de questões em simulados; e o avaliar e o criar ao desenvolver seus próprios métodos de resolução e de avaliação de resoluções de colegas.

Para além dos educandos, a estrutura da taxionomia de Bloom permite estimular os educadores a auxiliarem seus discentes, de forma estruturada e consciente, a adquirirem competências específicas a partir da percepção da necessidade de dominar habilidades mais simples (fatos) para, posteriormente, dominar as mais complexas (conceitos) (FERRAZ; BELHOT, 2010).

\subsection{Estudos de preparação na UCS}

No planejamento das oficinas, priorizou-se a construção de ambientes com ênfase na aprendizagem ativa, colocando as estudantes como protagonistas da própria aprendizagem. A atuação das bolsistas de graduação foi orientada para conduzir as atividades de forma que as estudantes do ensino fundamental e médio se sentissem motivadas a aplicar e a produzir conhecimento, interagir com os pares e compartilhar suas experiências, como parte do processo educacional. Com efeito, a aprendizagem ativa pode ser resultante de qualquer método instrucional que engaje os estudantes no processo de aprendizagem, o que requer, portanto, que eles executem atividades significativas e raciocinem sobre o que estão fazendo (ELMÔR-FILHO et al, 2019).

A estratégia utilizada para motivar e engajar as alunas na resolução dos problemas matemáticos foi a estratégia de aprendizagem ativa conhecida como Desafio em Grupos, que integra os estudantes em atividades de intensa interação, cooperação e pensamento coletivo. Tem caráter lúdico, com o poder de melhorar a autoestima dos estudantes e promover um ambiente descontraído e envolvente, servindo como estímulo para a interação, pois gera interesse e prazer em relacionar-se com os colegas (ELMÔR-FILHO et al, 2019).

Freire (1996), também chama a atenção para a importância do respeito à autonomia e à identidade do estudante, uma vez que através desse meio ocorre a mobilização de seus conhecimentos que o impulsiona para novas descobertas e concepções.

Não é possível respeito aos educandos, à sua dignidade, se não se levam em consideração as condições em que eles vêm existindo, se não se reconhece a importância dos conhecimentos de experiência feitos com que chegam à escola. $O$ respeito devido à dignidade do educando não me permite subestimar, pior ainda, zombar do saber que ele traz consigo para a escola (FREIRE, 1996).

\subsection{Estudos de preparação na UCS}

A primeira etapa das oficinas foi de preparação teórica e procedimental e ministrada por um mestrando intercambista para as bolsistas de graduação, preparandoas para posterior aplicação nas escolas. A partir de um levantamento dos temas mais recorrentes nas provas da OBMEP, cada encontro foi focado em um dos tópicos de matemática dentre os seguintes: regras de padrões; permutações de contagem e combinações; lógica; diagramas; subtração e subtração visual; ordem de operações; desigualdades; geometria analítica; frações; estatísticas básicas; expressões com incógnitas e equações e percentuais.

Nos encontros de preparação na UCS, inicialmente o tema do dia era apresentado e resolviam-se questões da OBMEP, de provas anteriores, relacionadas ao conteúdo. Durante tempos pré-determinados, cada bolsista resolvia individualmente a questão e, a seguir, eram promovidas discussões sobre dificuldades e possíveis técnicas de resolução, 
considerando o público alvo. Dessa forma, através da interação e compartilhamento do conhecimento, garantiu-se que diferentes resoluções fossem exploradas e que todas as bolsistas estivessem preparadas para a aplicação nas escolas.

Nesta etapa ainda foi possível observar as maiores dificuldades no desenvolvimento das questões com diferentes perspectivas e, ao identificar os problemas, pôde-se dar ênfase na explicação desses pontos de prováveis dificuldades na aplicação nas escolas. Ao final dos encontros de preparação, também discutiu-se sobre a técnica mais indicada para cada questão, definido um "passo a passo" que traria bons resultados.

\subsection{Avaliação Diagnóstica}

No primeiro encontro da etapa nas escolas foi realizada uma avaliação diagnóstica, preparada pelas bolsistas de graduação, com questões fáceis, médias e difíceis, abrangendo todos os tópicos já citados. Cada participante resolveu a avaliação individualmente, com um tempo pré-determinado de, no máximo. 2 horas. Foi solicitado, também, que as meninas resolvessem as questões de forma detalhada, garantindo assim, a possibilidade de identificar a técnica que cada estudante utilizou, para que fosse analisado exatamente em que parte do desenvolvimento aconteceram os erros.

Durante a análise, foram quantificados os erros e acertos de cada questão, e nos encontros posteriores foram enfatizadas as questões com conteúdos que apresentaram as maiores defasagens, de acordo com as particularidades de cada escola. A matemática é uma ciência básica que é utilizada em diversas áreas do conhecimento, portanto é fundamental que as estudantes apresentem bom nível de conhecimento dos conteúdos.

\subsection{Estudos de preparação nas escolas}

Dentre as cinco escolas participantes do projeto havia diferentes níveis de ensino e estes compreendiam distintos níveis de complexidade considerados. Três das escolas são de ensino fundamental e ensino médio, uma somente de ensino fundamental e, por fim, uma escola somente de ensino médio, todas da região de abrangência da UCS.

A programação das oficinas foi aplicada durante 6 semanas, no turno contrário ao que as alunas estudavam. Esse período abrangia 4 horas de estudo em um dia da semana, com intervalo de 30 minutos. Ainda que tenha como objetivo principal o incentivo às mulheres na ciência e na matemática, propiciando estímulo e autoconfiança para as meninas, optou-se por permitir a participação de ambos os gêneros, ou seja, meninos e meninas.

Ao trabalhar com equipes mistas, foi possível adequar o planejamento ao ambiente da escola e sua rotina, tendo em vista que as turmas são compostas por meninos e meninas. Assim sendo, encontrou-se ainda mais benefícios proporcionados pelo trabalho partilhado. Freire (1996) defende a dialogicidade verdadeira, onde os indivíduos aprendem e crescem na diferença, criando um elo de respeito à autonomia e à opinião do outro.

As turmas presentes no contraturno escolar eram constituídas, em média, por 20 estudantes do $6^{\underline{0}}$ ano ao $9^{\circ}$ ano do ensino fundamental e 20 do $1^{\circ}$ ano ao $3^{\circ}$ ano do ensino médio. Em escolas onde o número de alunos interessados nas oficinas extrapolasse o limite para uma boa qualidade da aplicação da metodologia, um novo dia da semana era escolhido para possibilitar a participação de todos, evitando a dispersão da atenção e do foco dos estudantes.

Em alguns casos onde houve certa flexibilidade de horários, algumas questões foram trabalhadas durante as aulas de matemática e, com isso, dando oportunidade a alunos que, por motivos pessoais, não se faziam presentes no contraturno escolar, ainda 
que, majoritariamente, a aplicação da metodologia se deu no turno contrário, como atividade extracurricular.

Seguindo o planejamento, antes da aplicação da estratégia Desafio em Grupos, era realizada uma breve revisão de conceitos, na tentativa de nivelar os conhecimentos prévios das estudantes. A abordagem nesta etapa se deu de forma expositiva, de no máximo 15 minutos, com uma introdução envolvendo o tópico matemático em estudo e o melhor meio de resolução de questões relacionadas ao mesmo.

Notou-se que grande parte dos participantes apresentavam dificuldades na base teórica, e praticamente todos apresentaram problemas na interpretação das questões. Entretanto, com o tempo, foi possível observar progressos na realização das atividades, promovendo debates de respostas, proporcionando assim, o desenvolvimento de competências e habilidades que, inclusive, colaboram para maior segurança e clareza no entendimento das questões.

O Desafio em Grupos contém 5 etapas de aplicação. Na etapa 1, são fornecidas instruções acerca da execução da atividade, informando aos estudantes, o tema principal da dinâmica. Para cada encontro foram separadas questões de mesma natureza contemplando um tópico, dentre os mencionados na subseção 2.2.

$\mathrm{Na}$ execução da etapa 2, informou-se a divisão das equipes e cada grupo foi representado por dois de seus componentes, que resolviam no quadro os problemas sorteados em cada rodada. Todos foram pelo menos uma vez ao quadro e a cada acerto somava-se um ponto para a equipe. Os grupos foram diversificados ao longo dos encontros, para que, dessa forma, fosse possível a socialização de conhecimentos, com o maior número possível de colegas.

$\mathrm{Na}$ etapa 3, cada grupo apresentava a resolução de um problema e os colegas acompanhavam a resolução e anotavam em seus cadernos. Os participantes que estavam no quadro não tinham acesso a nenhum material de apoio, mas era permitida a interação com seus colegas de equipe, que estavam nas mesas. $\mathrm{Na}$ etapa 4, as equipes avaliavam as resoluções dos adversários $e$, nos casos onde não havia nada a acrescentar, o grupo ganhava a pontuação. Já na situação em que outro grupo identificava algum erro no desenvolvimento da questão apresentada pelo colega, esse grupo recebia a pontuação.

$\mathrm{Na}$ etapa 5, a bolsista de graduação discutia as questões e suas resoluções, esclarecendo dúvidas e fazendo os devidos registros. Esse momento, na aplicação do Desafio em Grupos, é extremamente relevante, pois faz com que os erros sejam percebidos e os métodos aperfeiçoados.

Com o passar das semanas, os grupos foram sendo diminuídos, para que, desse modo, os participantes desenvolvessem autonomia e confiança para resolver os problemas matemáticos sozinhos, preparando-se, assim, para a etapa posterior - a prova da $1^{\underline{a}}$ fase.

Ao final de cada oficina o grupo vencedor era presenteado com uma recompensa simbólica, mas todos os estudantes que participaram da dinâmica também foram reconhecidos e presenteados. Essa pequena competição fez com que todos fossem encorajados e melhorassem o seu desempenho e produtividade individual, buscando estar no próximo grupo vencedor.

De posse dos relatos concebidos pelas professoras das escolas participantes do Projeto, bem como cientes da dificuldade apontada pelas bolsistas de graduação durante a realização das oficinas de preparação, notou-se uma grande lacuna quanto à resolução de provas longas, surgindo assim a necessidade de sanar questionamentos elencados pelas estudantes. 
Criou-se, então, um momento propício para troca de ideias, no qual instruções pertinentes foram repassadas aos estudantes, buscando a não desistência frente a questões de maior complexidade. Ferramentas auxiliares fornecidas pelo mestrando intercambista foram pautas discutidas durante os encontros com as bolsistas da graduação, como a utilização do método de exclusão de alternativas, para o caso de provas objetivas, e ainda, quando muitas questões assemelham-se ou apresentam desordem em seu enunciado, sugere-se iniciar pelos problemas mais fáceis e organizados.

\subsection{Olimpíadas nas Escolas}

Após a etapa de preparação, foi realizada a Fase 1 da OlimMat nas escolas. A prova foi destinada a todos os alunos das escolas e, ficou a critério de cada professor, escolher se iriam implementar o evento para toda a escola ou somente para as turmas que participaram da preparação. Nas escolas, os estudantes foram separados em salas pelos níveis de aplicação das provas (Nível 1, Nível 2 ou Nível 3) e cada sala dispunha de um professor ou responsável, para o acompanhamento.

As provas foram desenvolvidas nos moldes da Fase 1 da OBMEP, ou seja: prova objetiva, de caráter classificatório composta por vinte questões de múltipla escolha, valendo um ponto cada, totalizando vinte pontos, onde cada questão dispunha de cinco opções de resposta ( $A, B, C, D$ e E), dentre as quais apenas uma delas era a correta. $A$ duração da prova foi de duas horas e trinta minutos.

Após a correção das provas, os estudantes e seus professores de Matemática que obtiveram os melhores desempenhos - foram premiados. Os três primeiros meninos e as três primeiras meninas classificadas, de cada um dos níveis receberam medalhas de ouro, prata e bronze e seus professores de Matemática obtiveram certificados de honra ao mérito.

\subsection{Olimpíadas na UCS}

Os estudantes que realizaram a prova da fase 1 e foram classificados, participaram de uma nova prova representando sua escola na fase 2. A aplicação da segunda prova foi realizada na UCS - Campus Sede, quando 72 estudantes participaram. A prova foi elaborada com questões dissertativas nos moldes da OBMEP. As bolsistas do projeto ficaram a cargo de fiscalizar a realização do evento, a fim de evitar fraudes.

A solenidade de premiação ocorreu no mesmo local da prova, com representantes das cinco escolas participantes, alunos e familiares. Assim como na fase 1, como critério da premiação da segunda fase, os participantes foram separados em duas categorias: melhores meninas e melhores meninos, recebendo também medalhas de ouro, prata e bronze.

Os professores receberam certificados de honra ao mérito e um livro de Matemática. As escolas participantes foram premiadas com troféus de primeiro, segundo e terceiro lugar, com base no desempenho de seus estudantes, por acúmulo de pontos, de acordo com os mesmos critérios de premiação dos professores. Foram também concedidos kits livros às cinco escolas. O destaque ficou a cargo da premiação do nível 3 , pois os medalhistas de ouro das duas categorias ganharam também uma bolsa de estudos na universidade, podendo escolher dentre os cursos de exatas.

\section{Resultados}

Ao longo da aplicação da estratégia Desafio em Grupos, foi perceptível o gradativo aumento de participação e entusiasmo dos estudantes frente à proposta. Percebeu-se 
uma notável melhora durante os bate-papos e a integração entre os membros das equipes.

Durante a aplicação da avaliação, na $1^{\text {a }}$ fase, todos os estudantes respeitaram as regras e demonstraram-se empenhados na realização das atividades, bem como respeitaram os horários e aguardaram os demais colegas finalizarem suas avaliações.

Dentre as 5 instituições participantes, estimou-se a participação de 150 estudantes no Nível 1, sendo 52\% meninas. No nível 2, houve a participação de 110 estudantes, no qual $48 \%$ são meninas. Já para o nível 3, foram contabilizados 230 alunos, sendo 49\% meninas. Com estes dados, pode-se confirmar o resultado promissor que a estratégia aplicada ofereceu às meninas.

Diante da análise das respostas obtidas nos três níveis, é possível afirmar que os resultados foram satisfatórios, uma vez que as estudantes que se destacaram obtiveram médias inferiores na OBMEP (ocorrida em 21 de maio de 2019). O aumento significativo nas médias obtidas na OlimMat - 2019 pode ter sido propiciado pelos estudos realizados durante o Projeto EMC\&T, desde março de 2019, no contraturno escolar, somado à estratégia Desafio dos Grupos, que intensificou os estudos e aguçou o interesse das estudantes.

As estudantes selecionadas para realizar a $2^{\mathrm{a}}$ fase da OlimMat demonstraram-se empenhadas e dedicadas na resolução dos problemas propostos para estudo, apresentando assertividade nas escolhas e assiduidade na participação dos encontros. Algumas estudantes foram além, estudando, em casa, por meio da resolução de provas de edições anteriores da fase 2 da OBMEP. Essas estudantes, diariamente procuravam os professores de Matemática da escola, para esclarecer dúvidas ou questões que estavam buscando resolver em seus estudos. Atitudes como esta, demonstram que, de fato, houve uma mudança de postura destes educandos, que sentiram-se motivados e incentivados a buscar mais, gerando, além de conhecimento e desenvolvimento do raciocínio lógico-matemático, autonomia e interesse por aprender.

Durante a premiação da OlimMat, subdividida em premiação para meninos e em premiação para meninas, foi possível destacar o sentimento de reconhecimento, capacidade e competência demonstrado pelas meninas. A possibilidade de alcançar seus objetivos através da dedicação e dos estudos deu a cada participante da OlimMat a consciência de que são capazes e são merecedoras do que elas objetivam.

\section{Conclusão}

A partir da aplicação desta sequência de atividades, foi possível perceber uma grande evolução nas meninas, tanto nos âmbitos cognitivo e social quanto nos âmbitos comportamental e educacional. Além disso, foi evidente o desenvolvimento em termos de autonomia e autoconfiança.

A Olimpíada de Matemática representou uma motivação em prol de atividades dinâmicas, atuando como facilitador na desconstrução de sentimentos negativos em relação à aprendizagem de ciências exatas e à dificuldade de compreender seus conceitos. Ao elaborar as oficinas, toda equipe se preocupou em trazer explicações práticas e descomplicadas para os jovens, com o intuito de concretizar o aprendizado.

Logo, constata-se que o trabalho realizado trouxe benefícios tanto para quem foi destinado, quanto para quem o aplicou, pois a educação é uma via de mão dupla que visa o desenvolvimento constante de todos os envolvidos.

Diante disso promove-se o início de um processo de rompimento de paradigmas estereótipos que segregam meninas e mulheres. Com a extinção de tais preconceitos, todos podem exercer suas escolhas com mais liberdade, podendo desenvolver melhor suas habilidades e participar de maneira significativa no avanço do conhecimento 
científico e tecnológico. Com isso, é importante ressaltar que se faz de extrema importância a aplicação de programas de incentivo e valorização da participação feminina nas áreas de STEM.

\title{
Agradecimentos
}

Os autores agradecem o apoio do CNPq e da UCS.

\section{REFERÊNCIAS}

ELMÔR-FILHO, Gabriel et al. Uma nova sala de aula é possível: aprendizagem ativa na educação em engenharia. Rio de Janeiro: LTC, 2019.

FERRAZ, Ana; BELHOT, Renato. Taxonomia de Bloom: revisão teórica e apresentação das adequações do instrumento para definição de objetivos instrucionais. Gest. Prod., São Carlos, v. 17, n. 2, p. 421-431, 2010.

FREIRE, Paulo. Pedagogia da autonomia: saberes necessários à prática educativa. São Paulo: Paz e Terra, 1996.

IMPA. O desempenho das meninas nas olimpíadas. 2019. Disponível em: http://www.obmep.org.br/noticias.do?id=601. Acesso em: 03 abr. 2021.

OBMEP. Obmep em números. Disponível em: http://www.obmep.org.br/emnumeros.htm. Acesso em: 01 abr. 2021.

\section{MATHEMATICS OLYMPIAD: ENCOURAGING MORE GIRLS TO PARTICIPATE}

\begin{abstract}
In this article, we present the subproject Mathematics Olympiad that integrated the project Encouraging Girls in Exact Sciences, Engineering, and Information Technology, at the University of Caxias do Sul. The referred subproject contemplated both planning and execution of workshops to prepare students for Mathematics Olympiad and was developed by a girls' team of undergraduate students, guided by university instructors, and assisted, in the initial stage, by an exchange student from University of Verona, Italy. For the planning of the workshops, the students raised recurring themes in Brazilian Mathematics Olympiad for Public Schools and carried out diagnostic evaluations to identify difficulties of co-executing schools' students. The workshops were developed based on the active learning strategy "Challenge in Groups" for the resolution of questions and problems already applied in Brazilian Mathematics Olympiad for Public Schools. At each meeting, the number of the group members was reduced, so that little by little the students could be able to work individually. After this stage of preparation, the girls 'team of undergraduate students selected new questions and assisted in the organization and conduct of mini Olympiad (Phase 1) with a classificatory nature. Five public schools from the UCS coverage region participated, with all students interested and divided by levels: Level 1 for 6th and 7th grades and Level 2 for 8th and 9th grades of Elementary School, and Level 3 for High School. The three students with the best performance at each level went on to Phase 2, representing their schools at the University of Caxias do Sul Mathematics Olympiad 2019. In Phase 2, the undergraduate students sought questions
\end{abstract}


from previous Olympics of greater complexity to challenge and highlight the best students with gold, silver, and bronze medals, and their schools with first, second and third place trophies. In developing this important study and engagement project for the co-executing schools' students, the undergraduate students also collaborated to develop autonomy and self-confidence in the co-executing schools' students, encouraging them to participate in OBMEP.

Keywords: Mathematics Olympiad, Active Learning, Mathematics Workshops. 